\title{
Rendimento do feijoeiro comum em função da aplicação de fertilizantes minerais nitrogenados em cobertura
}

\author{
Common bean yield due to the application of nitrogen fertilizers in topdressing
}

\author{
Sulian Junkes Dal Molin* e Paulo Roberto Ernani
}

Recebido em 11/03/2016 / Aceito em 20/02/2017

\section{RESUMO}

Com a intenção de reduzir as perdas de nitrogênio (N) decorrente da adubação, vários fertilizantes nitrogenados modificados estão sendo disponibilizados aos agricultores. Este trabalho teve como objetivo avaliar a disponibilidade de $\mathrm{N}$ no solo e a resposta do feijoeiro a fontes de fertilizantes minerais nitrogenados modificados aplicados em cobertura. O experimento foi conduzido no município de Vacaria, estado do Rio Grande do Sul, sobre um Latossolo Bruno que apresentava $516 \mathrm{~g} \mathrm{~kg}^{-1}$ de argila, $\mathrm{pH}$ em água de 5,2 e $46 \mathrm{~g} \mathrm{~kg}^{-1}$ de matéria orgânica, onde havia um pomar de macieira nos últimos 20 anos. Os tratamentos foram constituídos pelos seguintes fertilizantes comerciais minerais: Ureia convencional, Super $\mathrm{N}^{\circledR}$, Kimcoat $\mathrm{N}^{\circledR}$, Nitro Mais ${ }^{\circledR}$, Super Nitro ${ }^{\circledR}$, Producote ${ }^{\circledR}$, Sulfammo Meta $29^{\circledR}$ e nitrato de amônio, todos na dose de $60 \mathrm{~kg}$ ha $^{-1}$ de N, além de um controle, sem aplicação de N. A eficiência dos fertilizantes foi avaliada por ocasião da adubação de cobertura. Foi avaliada a disponibilidade de $\mathrm{N}$ no solo, o teor de $\mathrm{N}$ nas folhas, teor de proteína nos grãos, a massa de 1000 grãos, e o rendimento de grãos. O rendimento médio de grãos foi de $3.770 \mathrm{~kg}$ $\mathrm{ha}^{-1} \mathrm{e}$ não foi afetado por nenhum dos fertilizantes aplicados em cobertura. Os fertilizantes nitrogenados também não afetaram nenhum dos atributos avaliados, incluindo a disponibilidade de $\mathrm{N}$ no solo, quantificada aos 21 dias após a aplicação. O Latossolo Bruno, com teor médio de matéria orgânica, sob condições de boa distribuição de precipitação pluviométrica, promoveu adequado suprimento de $\mathrm{N}$ para as plantas de feijão.

PALAVRAS-CHAVE: ureia protegida, fertilizantes de liberação lenta, eficiência de fertilizantes.

\section{ABSTRACT}

With the intention to reduce losses of nitrogen $(\mathrm{N})$ resulting from soil fertilization, several modified nitrogen fertilizers are being made available to growers. This study aimed to evaluate the response of common beans to nitrogen fertilizers applied in topdressing. The experiment was conducted in Vacaria, Southern of Brazil, on an Oxisol with $516 \mathrm{~g} \mathrm{~kg}^{-1}$ clay, $\mathrm{pH}=5.2$ and $46 \mathrm{~g} \mathrm{~kg}^{-1}$ organic matter. The experimental area was previously an apple orchard for twenty years. The treatments included the following commercial mineral fertilizers: conventional urea, Super $\mathrm{N}^{\circledR}$, Kimcoat $\mathrm{N}^{\circledR}$, Nitro Mais ${ }^{\circledR}$, Super Nitro ${ }^{\circledR}$, Producote ${ }^{\circledR}$, Sulfammo Meta $29^{\circledR}$ and ammonium nitrate, all applied at a rate of $60 \mathrm{~kg} \mathrm{ha}^{-1}$, in topdressing, in addition to a control without application of N. The availability of $\mathrm{N}$ in soil, $\mathrm{N}$ in the leaves, protein in the grain, mass of 1,000 grains, and grain yield was evaluated. The average grain yield across treatments was $3,770 \mathrm{~kg}$ $\mathrm{ha}^{-1}$ and was not affected by any $\mathrm{N}$ fertilizer applied at topdressing. In addition, $\mathrm{N}$ fertilizers did not affect any soil and plant evaluated attribute, including $\mathrm{N}$ availability in the soil 21 days after application. Thus, soil organic matter supplied all $\mathrm{N}$ needed to the plants, mainly due to the good rainfall distribution.

KEYWORDS: urea coated, slow release fertilizers, fertilizer efficiency.

\section{INTRODUÇÃO}

O feijão (Phaseolus vulgaris L.) é uma importante fonte de alimento e de renda para os agricultores. Seu cultivo foi historicamente realizado

Universidade do Estado de Santa Catarina, Lages, SC, Brasil.

*Autor para correspondência <sulian.ta@hotmail.com> 
por agricultores familiares devido ao alto custo de mão de obra. Porém, com a mecanização da cultura, adequação das técnicas de cultivo e ao alto valor do produto, médios e grandes produtores incorporaram o cultivo do feijoeiro em seus sistemas de cultivo. Isso fez com que a área cultivada no município de Vacaria, RS, aumentasse consideravelmente nos últimos anos.

O feijoeiro é considerado uma espécie altamente exigente em nutrientes, com destaque para o nitrogênio (N) (AMARAL et al. 1980). Parte desta demanda de $\mathrm{N}$ pelas plantas pode ser suprida através da fixação biológica, porém estudos têm revelado a necessidade de complementação mineral de $\mathrm{N}$ para se alcançar altos rendimentos (VARGAS et al. 2000, PELEGRIN et al. 2009, BRITO et al. 2015).

Dos fertilizantes minerais nitrogenados a ureia é o mais utilizado nas adubações. A alta concentração de $\mathrm{N}$ facilita o transporte, a estocagem e a aplicação, reduzindo o custo por unidade de $\mathrm{N}$ em relação aos demais fertilizantes. Porém, quando a ureia é aplicada sobre a superfície do solo pode proporcionar perdas consideráveis por volatilização de amônia (OLIVEIRA et al. 2014). Essas perdas são devido à elevação do $\mathrm{pH}$ ao redor dos grânulos promovida pela urease ao hidrolisar a ureia.

Recentemente vários fertilizantes nitrogenados foram disponibilizados no mercado com o objetivo de reduzir as perdas por volatilização de amônia. $O$ principal mecanismo utilizado nesses fertilizantes é de diminuir a velocidade de hidrólise da ureia e a inibição temporária da atividade da urease, retardando a transformação de $\mathrm{N}$ amídico da ureia em amônio e, consequentemente, a transformação de amônio em amônia ou nitrato (CHIEN et al. 2009).

Estes fertilizantes podem ser divididos em dois grupos: os fertilizantes de liberação lenta ou controlada e os fertilizantes estabilizados. Os fertilizantes nitrogenados de liberação lenta, ou controlada, são recobertos ou encapsulados, cujo processo tem a finalidade de diminuir a solubilidade dos mesmos relativamente aos fertilizantes convencionais. Nesse grupo se destacam os fertilizantes nitrogenados recobertos com enxofre e ou com polímeros. O segundo grupo é composto por aditivos que inibem a nitrificação e a urease, sendo que o NBPT (n-(nbutyl) tiofosfórico triamida) é o composto com maior destaque neste grupo (CANTARELLA 2007).

A hipótese deste trabalho é que os fertilizantes nitrogenados de liberação lenta ou controlada e aqueles com inibidor da urease são mais eficientes no fornecimento de $\mathrm{N}$ para o feijoeiro, em função de proporcionarem menores perdas por volatilização de amônia relativamente à ureia convencional. O objetivo deste trabalho foi avaliar o efeito da aplicação de fertilizantes nitrogenados em cobertura na disponibilidade de $\mathrm{N}$ no solo e no rendimento de grãos do feijoeiro.

\section{MATERIAL E MÉTODOS}

O estudo foi conduzido em condições de campo em uma propriedade comercial, no município de Vacaria, estado do Rio Grande do Sul, na safra $2014 / 2015$, onde havia um pomar de macieira durante os últimos 20 anos. O local está a $955 \mathrm{~m}$ de altitude e possui as seguintes coordenadas geográficas: latitude $28^{\circ} 30^{\prime} 33,22^{\prime \prime}$ ao sul e longitude $50^{\circ} 48^{\prime} 36,45^{\prime \prime}$ ao oeste. Na região, o clima é do tipo $\mathrm{Cfb}$ (temperado úmido, com verões amenos, segundo a classificação de Köppen). A precipitação pluviométrica acumulada e a temperatura média durante o período de condução do experimento foram de $376 \mathrm{~mm}$ e $21,4{ }^{\circ} \mathrm{C}$ (Figura 1). $\mathrm{O}$ experimento foi conduzido sobre um Latossolo Bruno contendo $516 \mathrm{~g} \mathrm{~kg}^{-1}$ de argila; $\mathrm{pH}$ em água de 5,2; $46 \mathrm{~g} \mathrm{~kg}^{-1}$ de matéria orgânica; $116 \mathrm{mg} \mathrm{dm}^{-3} \mathrm{de} \mathrm{K}$ (Mehlich-1); 1,45 $\mathrm{mg} \mathrm{dm}^{-3}$ de P (Mehlich-1); 9,0 $\mathrm{cmol}_{\mathrm{c}}$ $\mathrm{dm}^{-3}$ de $\mathrm{Ca} ; 1,4 \mathrm{cmol}_{\mathrm{c}} \mathrm{dm}^{-3}$ de $\mathrm{Mg} ; 0,3 \mathrm{cmol}_{\mathrm{c}} \mathrm{dm}^{-3} \mathrm{de}$ Al e $11,03 \mathrm{cmol}_{\mathrm{c}} \mathrm{dm}^{-3}$ de $\mathrm{CTC}_{\text {efetiva }}$ determinados por métodos propostos por TEDESCO et al. (1995).

A semeadura do feijão foi realizada com a cultivar BRS Estilo do grupo comercial carioca, em janeiro de 2015 utilizando uma semeadora de plantio direto. $\mathrm{O}$ espaçamento entre linhas foi de $0,45 \mathrm{~m}$ com 13 sementes por metro linear, totalizando um estande estimado de 280.000 sementes por hectare. Foram aplicados $200 \mathrm{~kg} \mathrm{ha}^{-1}$ de monoamônio fosfato no momento da semeadura, em todos os tratamentos, equivalendo a uma dose de $18 \mathrm{~kg} \mathrm{ha}^{-1}$ de $\mathrm{N}$.

O delineamento experimental utilizado foi o de blocos casualizados com nove tratamentos e quatro repetições. As unidades experimentais tinham 5,0 m de comprimento e oito linhas de plantas, distanciados em $0,45 \mathrm{~m}$, totalizando $18 \mathrm{~m}^{2}$.

Nos tratamentos foram utilizados fertilizantes minerais convencionais: Nitrato de Amônio (32\% de $\mathrm{N})$ e Ureia $(45 \%$ de $\mathrm{N})$; fertilizantes minerais estabilizados e de liberação lenta ou controlada: Sulfammo Meta $29^{\circledR}\left(29 \%\right.$ de N), Super $N^{\circledR}(45 \%$ de N), Nitro Mais ${ }^{\circledR}\left(45 \%\right.$ de N), Super Nitro ${ }^{\circledR}(45 \%$ de N), Producote ${ }^{\circledR}\left(39 \%\right.$ de N) e Kimcoat $N^{\circledR}(45 \%$ de N); 


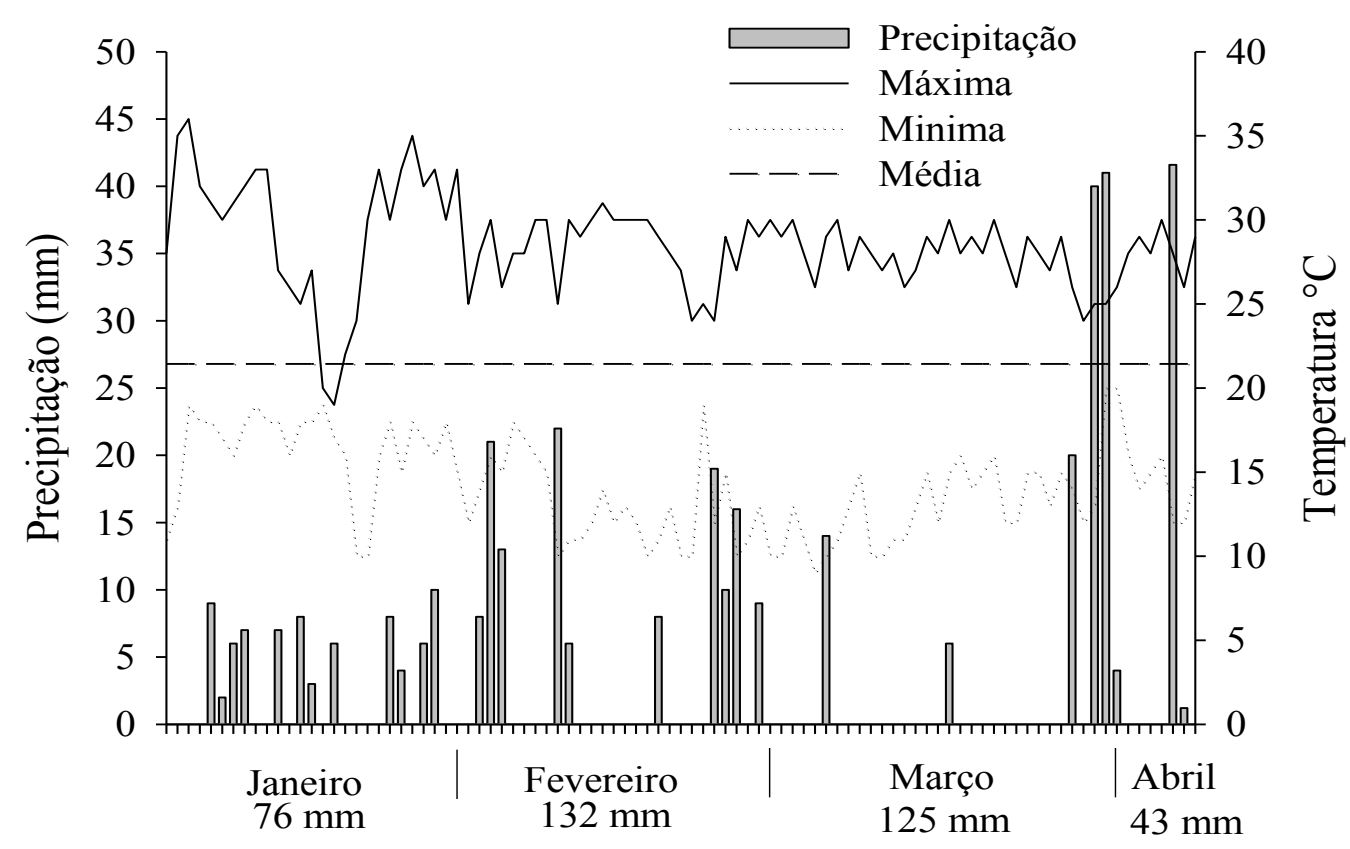

Figura 1. Distribuição da temperatura e da precipitação pluviométrica diária na área experimental ocorrida da semeadura à colheita.

Figure 1. Daily temperature and rainfall distribution in the experimental area from sowing through harvest.

além de um controle, sem adição de N. Os fertilizantes foram aplicados na dose de $60 \mathrm{~kg} \mathrm{ha}^{-1} \mathrm{de} \mathrm{N}$ baseada no teor de matéria orgânica do solo e em uma expectativa de rendimento de $3.000 \mathrm{~kg} \mathrm{ha}{ }^{-1}$ (CQFS-RS/SC 2004), manualmente, sobre a superfície do solo, sem incorporação, 23 dias após a semeadura. A eficiência dos fertilizantes foi, portanto, avaliada somente por ocasião da adubação de cobertura. A umidade gravimétrica do solo no momento da aplicação era de $0,39 \mathrm{~g} \mathrm{~g}^{-1}$.

A concentração de $\mathrm{N}$ nos fertilizantes (Tabela 1) foi determinada pelo método de arraste de vapores em aparelho semimicro Kjeldahl, de acordo com metodologia proposta por TEDESCO et al. (1995). Foram utilizadas duas formas de extração: diluição em água destilada, na concentração de $1000 \mathrm{mg} \mathrm{dm}^{-3}$ de N, e digestão sulfúrica (TEDESCO et al. 1995). Em ambas, os fertilizantes foram previamente moídos e passados em peneira com malha de $0,3 \mathrm{~mm}$.

As aplicações de herbicidas, fungicidas e inseticidas foram efetuadas de acordo com as recomendações técnicas para a cultura do feijoeiro (CTSBF 2012).

Em cada parcela foram coletadas cinco subamostras de solo, na profundidade de 0 a $20 \mathrm{~cm}$, antes da aplicação dos tratamentos, aos 22 dias após a semeadura, e 21 dias após a aplicação dos tratamentos para determinar $\mathrm{N}$ mineral. Esse foi extraído com solução de $\mathrm{KCl} 1 \mathrm{~mol} \mathrm{~L}^{-1}$ e determinado pelo método de arraste de vapores em aparelho semimicro Kjeldahl (TEDESCO et al. 1995). Aos 44 dias após a semeadura, início do florescimento, foram coletadas 30 folhas de plantas aleatórias por parcela, sendo o primeiro trifólio expandido do ápice em direção à raiz (MALAVOLTA 2006). As folhas foram secas em estufa de circulação de ar a $65^{\circ} \mathrm{C}$ até atingirem peso constante, moídas e submetidas à digestão sulfúrica, para determinação do teor de $\mathrm{N}$ pelo método de arraste de vapores em aparelho semimicro Kjeldahl (TEDESCO et al. 1995).

As avaliações de disponibilidade de $\mathrm{N}$ no solo, do teor de $\mathrm{N}$ nas folhas e do rendimento de grãos e seus componentes foram realizadas em uma área útil de $7,30 \mathrm{~m}^{2}$, correspondendo a seis linhas centrais com dimensões de $2,70 \mathrm{~m}$. A colheita foi realizada de maneira manual com corte das plantas rente ao solo, com auxílio de tesouras de poda. A seguir, as plantas foram recolhidas para posterior debulha, realizada em implemento batedor acoplado em trator. A umidade dos grãos foi determinada pela diferença da massa úmida e a massa seca em estufa de circulação de ar a $65^{\circ} \mathrm{C}$ até atingirem peso constante. A produtividade foi expressa contendo $13 \%$ de umidade. Uma amostra de grãos de cada parcela foi obtida para determinar a massa de mil grãos. 
Tabela 1. Porcentagem de $\mathrm{N}$ nos fertilizantes determinada pelo método de arraste de vapores em aparelho semimicro Kjeldahl (TEDESCO et al. 1995) com duas formas de extração.

Table 1. Percentage of $N$ in the fertilizers determined by the steam distillation method in semi-micro Kjeldahl equipment (TEDESCO et al. 1995) with two methods of extraction.

\begin{tabular}{|c|c|c|}
\hline & Digestão Sulfúrica $^{(1)}$ & Diluída em água $^{(2)}$ \\
\hline & \multicolumn{2}{|c|}{-------------- \% de N -------------- } \\
\hline Ureia & 43 & 0 \\
\hline Super N & 43 & 0 \\
\hline Kimcoat N & 42 & 0 \\
\hline Super Nitro & 43 & 0 \\
\hline Producote & 39 & 0 \\
\hline Nitro Mais & 42 & 0 \\
\hline $\mathrm{NH}_{4} \mathrm{NO}_{3}$ & 10 & 34 \\
\hline Sulfammo Meta 29 & 30 & 4 \\
\hline $\mathrm{KNO}_{3}{ }^{(3)}$ & 0 & 14 \\
\hline \multicolumn{3}{|c|}{$\begin{array}{l}\text { (1) Extração de } \mathrm{N} \text { através de digestão sulfúrica dos fertilizantes (TEDESCC } \\
\text { et al. 1995). } \\
\text { (2) Extração de } \mathrm{N} \text { através da diluição dos fertilizantes em água destilada } \mathrm{n} \\
\text { concentração de } 1000 \mathrm{mg} \mathrm{L}^{-1} \text {. }\end{array}$} \\
\hline
\end{tabular}

O teor de proteína no grão foi determinado em amostra previamente seca em estufa de circulação de ar a $65{ }^{\circ} \mathrm{C}$ até peso constante, moída e submetida à digestão sulfúrica. Sendo o teor de $\mathrm{N}$ determinado pelo método de arraste de vapores em aparelho semimicro Kjeldahl (TEDESCO et al. 1995) e multiplicado por 6,25 para se obter o teor de proteína, uma vez que o teor médio de $\mathrm{N}$ nas proteínas é de $16 \%$.

Os dados foram submetidos ao teste $\mathrm{F}(\mathrm{p} \leq 0,05)$ e quando alcançado significância a comparação entre as médias foi realizada pelo teste de Tukey $(\mathrm{p} \leq 0,05)$ com auxílio do software estatístico Assistat (SILVA \& AZEVEDO 2006).

\section{RESULTADOS E DISCUSSÃO}

Não houve efeito da aplicação dos fertilizantes minerais no teor de nitrogênio nas folhas do feijoeiro (Tabela 2). Os valores variaram entre 42,19 e 47,94 g $\mathrm{kg}^{-1}$, e são considerados acima da faixa adequada de acordo com ROSOLEM \& MARUBAYASHI (1994), entretanto, um pouco abaixo do valor considerado adequado por MALAVOLTA (2006), que é de $52,00 \mathrm{~g} \mathrm{~kg}^{-1}$. Os teores de $\mathrm{N}$ em folhas de feijoeiro normalmente aumentam com a aplicação de adubos nitrogenados (SANT'ANA et al. 2010), fenômeno esse não observado nesta pesquisa, à semelhança do encontrado por ALMEIDA et al. (2000) e FORNASIERI FILHO et al. (2007).

A massa de mil grãos também não foi influenciada pelos tratamentos (Tabela 2). A média da massa de mil grãos foi de 241,3 g. Outros estudos com feijoeiro mostram que a massa de mil grãos pode não variar com a aplicação de N (ALMEIDA et al. 2000, MOREIRA et al. 2013). Valores diferentes desses podem ser encontrados com diferentes cultivares (FORNASIERI FILHO et al. 2007) ou na mesma cultivar em anos diferentes (FARINELLI et al. 2006).

O teor de proteína nos grãos, estimado a partir de $\mathrm{N}$ nos grãos, foi semelhante entre os tratamentos, não havendo influência da aplicação de fertilizantes nitrogenados. Os valores de proteínas ficaram entre 18 e $20 \%$, um pouco abaixo dos valores encontrados em outros estudos (AMARAL et al. 1980, LONDERO et al. 2008, SANTOS et al. 2016). Esses valores mais baixos possivelmente são devido à variação nos teores de proteína em grãos de feijão de acordo com a cultivar e lugar cultivado (BURATTO et al. 2009).

A aplicação de $\mathrm{N}$ em cobertura, independente da fonte utilizada, não aumentou o rendimento de grãos do feijoeiro (Tabela 2). A produtividade média dos tratamentos foi de $3.770 \mathrm{~kg} \mathrm{ha}^{-1}$ ficando acima da média de produção para o estado do Rio Grande do Sul na safra 2014/2015 que foi de $1.580 \mathrm{~kg} \mathrm{ha}^{-1}$ (CONAB 
Tabela 2. Médias de teor de $\mathrm{N}$ nas folhas, massa de mil grãos, proteína no grão e produtividade de feijoeiro em função da adição de $\mathrm{N}$ em cobertura a partir de fertilizantes nitrogenados.

Table 2. Average concentration of $N$ in the leaves, weight of thousand grains, concentration of protein in the grain and grain yield due to addition of $N$ fertilizers.

\begin{tabular}{lcccc}
\hline Fertilizante* & N em folhas & Massa de mil grãos & Proteína no grão & Produtividade \\
\hline & $\mathrm{g} \mathrm{kg}^{-1}$ & $\mathrm{~g}$ & $\%$ & $\mathrm{~kg} \mathrm{ha}^{-1}$ \\
Controle & 42,93 & 239,5 & 19 & 3.710 \\
Ureia & 44,27 & 242,1 & 19 & 3.700 \\
Super N & 46,28 & 241,4 & 19 & 3.740 \\
Kimcoat N & 46,02 & 242,9 & 18 & 3.780 \\
NitroMais & 45,08 & 239,9 & 20 & 3.690 \\
Super Nitro & 42,19 & 240,8 & 20 & 3.720 \\
Producote & 45,35 & 241,4 & 19 & 3.980 \\
Sulfammo M. 29 & 47,94 & 240,2 & 19 & 3.800 \\
NH ${ }_{4} \mathrm{NO}_{3}$ & 46,12 & 243,3 & 20 & 3.790 \\
\hline Média & 45,13 & 241,3 & 19 & 3.770 \\
DMS & 8,99 & 12,52 & 2,40 & 580,05 \\
CV\% & 8,29 & 2,16 & 5,27 & 6,3 \\
F & $0,9036^{\mathrm{ns}}$ & $0,2563^{\mathrm{ns}}$ & $1,3634^{\mathrm{ns}}$ & $0,5780^{\mathrm{ns}}$ \\
\hline
\end{tabular}

* Adição equivalente a $60 \mathrm{~kg} \mathrm{ha}^{-1}$ de $\mathrm{N}$.

ns não significativo pelo teste $\mathrm{F}$ a $\mathrm{p} \leq 0,05$.

2015). A ausência de incremento no rendimento, assim como os demais componentes do rendimento, pela adição dos adubos nitrogenados ao solo provavelmente se deve a boa liberação de $\mathrm{N}$ oriunda da mineralização da matéria orgânica presente no solo, cujo teor médio de $46 \mathrm{~g} \mathrm{~kg}^{-1}$ é resultante, dentre outros fatores, do acúmulo de resíduos de plantas por vários anos sem revolvimento do solo durante o período em que foi conduzido o pomar de macieira.

Quanto ao teor de N mineral no solo antes da adubação de cobertura, observou-se que não houve diferença estatística entre os tratamentos, revelando haver boa disponibilidade do nutriente (Figura 2). O preparo do solo, após vários anos sem ocorrer o revolvimento do mesmo enquanto este foi cultivado com macieira, favoreceu a rápida mineralização da fração leve da matéria orgânica que é facilmente decomponível.

Aquantidade de $\mathrm{N}$ mineral no solo nos diferentes tratamentos manteve-se alta em relação à amostragem anterior a aplicação dos tratamentos, exceção ocorreu para o controle e para o Producote, onde os valores de $\mathrm{N}$ diminuíram (Figura 2). $\mathrm{O}$ tratamento Super Nitro apresentou a maior disponibilidade de $\mathrm{N}$, aproximadamente $88 \mathrm{~kg}$ de $\mathrm{N} \mathrm{ha}^{-1}$, diferindo dos tratamentos Producote e controle que apresentaram menor disponibilidade de $\mathrm{N}$ no solo na amostragem realizada 21 dias após a aplicação dos adubos em cobertura. A ausência de efeito significativo na disponibilidade de $\mathrm{N}$ no solo após a aplicação de fertilizantes em cobertura, reforçada pelas altas produtividades obtidas no tratamento controle (Tabela 2), demonstra que a adubação de semeadura (18 kg de $\mathrm{N} \mathrm{ha}^{-1}$ ) e a mineralização da matéria orgânica do solo foram suficientes para suprir a demanda de nitrogênio pela cultura, uma vez que após a aplicação dos fertilizantes em cobertura não promoveu incremento nos componentes de rendimento e tão pouco no rendimento de grãos.

A precipitação pluviométrica ao longo do experimento foi de $376 \mathrm{~mm}$ (Figura 1). Ocorreu uma boa distribuição desse volume no período em que a cultura se desenvolvia com acumulados mensais de $76,132,125$ e $43 \mathrm{~mm}$ nos meses janeiro, fevereiro, março e abril, respectivamente. Devido à precipitação pluviométrica de $10 \mathrm{~mm}$ que ocorreu no dia anterior à aplicação dos tratamentos, no momento da aplicação, a umidade gravimétrica do solo era de $0,39 \mathrm{~g} \mathrm{~g}^{-1}$, ficando acima da capacidade de campo para este solo (STRECK 2007). Até o quinto dia após a aplicação destes, ocorreu precipitação pluviométrica acumulada de $42 \mathrm{~mm}$ (Figura 1). Essas condições possibilitaram 


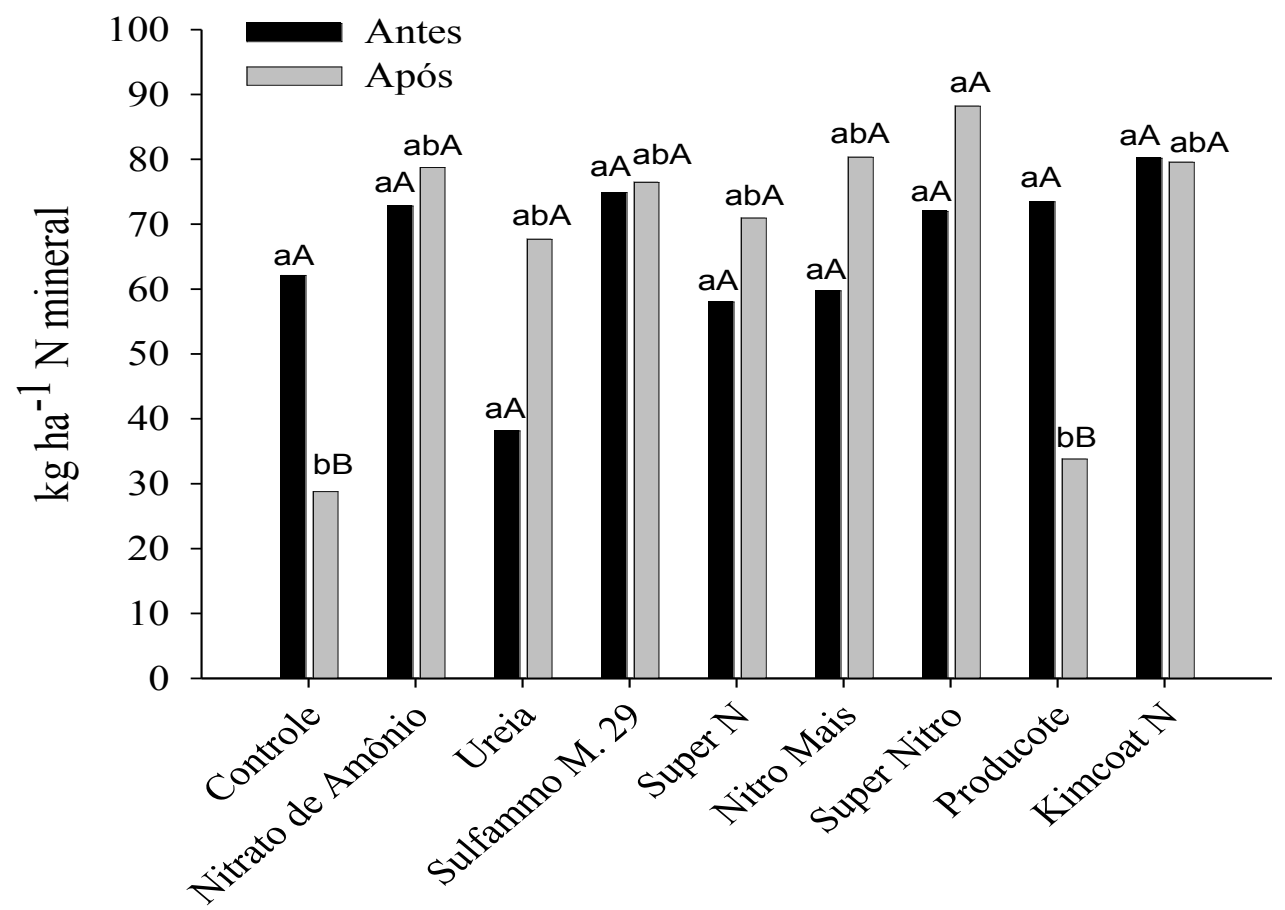

Figura 2 - Conteúdo de N mineral no Latossolo Bruno antes e aos 21 dias após a aplicação dos fertilizantes nitrogenados.

Médias seguidas da mesma letra, maiúscula para época de amostragem e minúscula para tratamento, não diferem pelo teste Tukey $(\mathrm{p} \leq 0,05)$.

Figure 2 - Mineral $N$ content in the Oxisol before and after 21 days of fertilizers addition.

Means followed by the same letter, uppercase for sampling time and lowercase for treatments do not differ by the Tukey test ( $p \leq 0.05)$.

rápida incorporação dos fertilizantes ao solo, podendo interferir na liberação de $\mathrm{N}$, mesmo para aqueles com características de liberação lenta ou controlada. Além disso, as boas condições de umidade do solo e a boa distribuição de chuvas ao longo do ciclo favorecem a mineralização da matéria orgânica do solo, com liberação de $\mathrm{N}$, e a mobilidade de $\mathrm{N}$ no solo por fluxo de massa, que é o mecanismo principal de suprimento de $\mathrm{N}$ às raízes, tornando a planta menos dependente de fontes externas desse nutriente.

Outro fator que possivelmente pode ter contribuído para o fornecimento adequado de $\mathrm{N}$ para as plantas foi a fixação biológica, através de associações com bactérias do gênero Rhizobium nativas do solo que nodulam as raízes (RUFINI et al. 2011), mesmo em áreas onde a cultura está sendo implantada pela primeira vez (LEMOS et al. 2003), fornecendo N para cultura do feijoeiro.

Os fertilizantes nitrogenados modificados para diminuir as perdas e aumentar a eficiência de uso do $\mathrm{N}$ pelas plantas tem apresentado divergência nos resultados. Alguns estudos mostram que estes fertilizantes podem diminuir as perdas por volatilização (NASCIMENTO et al. 2013) e aumentar absorção de $\mathrm{N}$ e o rendimento de grãos comparado a ureia convencional (DALAL 1975, SOUZA et al. 2013, FRAZÃO et al. 2014, LYU et al. 2015). Por outro lado, outros demonstram não haver redução de perdas de amônia por volatilização (FARIA et al. 2014, OLIVEIRA et al. 2014) e não influenciar o rendimento das culturas (VALDERRAMA, et al. 2014, BERNARDES et al. 2015) como encontrado neste trabalho.

Os dados deste trabalho mostram que a eficiência destes fertilizantes está associada a outros fatores que não somente ao mecanismo de proteção. As respostas ao uso destes fertilizantes diferem em função da forma de aplicação (CIVARDI et al. 2011), da disponibilidade hídrica (BERNARDES et al. 2015), da matéria orgânica do solo (WATSON et al. 1994, ANTISARI et al. 1996), da temperatura do solo (TASCA et al. 2011) e pH do solo (WATSON et al. 1994), além das condições edafoclimáticas favoráveis a mineralização da matéria orgânica como observado neste trabalho. 


\section{CONCLUSÃO}

A aplicação de fertilizantes nitrogenados em cobertura não alterou os componentes de rendimento e a produtividade do feijoeiro (cultivar BRS Estilo do grupo carioca). O Latossolo Bruno, com teor médio de matéria orgânica e mantido sem revolvimento nos últimos 20 anos, sob condições de boa distribuição de precipitação pluviométrica, promoveu adequado suprimento de $\mathrm{N}$ para as plantas de feijão. Aos 21 dias após a aplicação dos fertilizantes nitrogenados ao solo, em cobertura, nenhum deles aumentou a disponibilidade de $\mathrm{N}$ no solo.

\section{REFERÊNCIAS}

ALMEIDA C et al. 2000. Ureia em cobertura e via foliar em feijoeiro. Scientia Agrícola 57: 293-298.

AMARAL FAL et al. 1980. Exigências de nitrogênio, fósforo e potássio de alguns cultivares de feijoeiro (Phaseolus vulgaris L.). Anais.... Escola Superior de Agricultura Luiz Queiroz 37: 223-239.

ANTISARI LV et al. 1996. Effects of the urease inhibitor $\mathrm{N}$-(n-butyl) phosphorothioic triamide in low concentrations on ammonia volatilization and evolution of mineral nitrogen. Biology and Fertility of Soils 22: 196-201.

BERNARDES TG et al. 2015. Produtividade do feijoeiro irrigado em razão de fontes de adubo nitrogenado estabilizado e de liberação controlada. Revista Ceres 62: 507-513.

BRITO LF et al. 2015. Resposta do feijoeiro comum à inoculação com rizóbio e suplementação com nitrogênio mineral em dois biomas brasileiros. Revista Brasileira de Ciência do Solo 39: 981-992.

BURATTO JS et al. 2009. Variabilidade genética e efeito do ambiente para o teor de proteína em grãos de feijão. Acta Scientiarum. Agronomy 31: 593-597.

CANTARELLA H. 2007. Nitrogênio. In: NOVAIS RF et al. Fertilidade do solo. Viçosa: Sociedade Brasileira de Ciência do Solo. p.375-470.

CHIEN SH et al. 2009. Recent developments of fertilizer production and use to improve nutrient efficiency and minimize environmental impacts. In: SPARKS D. (Ed.). Advances in Agronomy. Burlington: Academic Press 102: 267-322.

CIVARDI EA et al. 2011. Ureia de liberação lenta aplicada superficialmente e ureia comum incorporada ao solo no rendimento do milho. Pesquisa Agropecuária Tropical 41: 52-59.

CQFS-RS/SC - Comissão de Química e Fertilidade do Solo. 2004. Manual de adubação e de calagem para os Estados do Rio Grande do Sul e de Santa Catarina. 10.ed. Porto Alegre. Sociedade Brasileira de Ciência do Solo. 400p.
CTSBF - Comissão Técnica Sul-Brasileira de Feijão. 2012. Informações técnicas para o cultivo de feijão na Região Sul brasileira. 2.ed. Florianópolis: Epagri. 157p.

CONAB - Companhia Nacional de Abastecimento. 2015. Acompanhamento da safra brasileira de grãos. Brasília. v.2 - Safra 2014/15, n.12 - Décimo segundo levantamento, set. 2015. Disponível em: http://www.conab.gov.br. Acesso em: 05 mai. 2016.

DALAL RC 1975. The use of urea and sulfur-coated urea for corn production in a tropical soil. Soil Science Society of America Journal 39: 1004-1005.

FARIA LDA et al. 2014. Hygroscopicity and ammonia volatilization losses from nitrogen sources in coated urea. Revista Brasileira de Ciência do Solo 38: 942-948.

FARINELLI $\mathrm{R}$ et al. 2006. Adubação nitrogenada de cobertura no feijoeiro, em plantio direto e convencional. Pesquisa Agropecuária Brasileira 41: 307-312.

FORNASIERI FILHO D et al. 2007. Resposta de cultivares de feijoeiro comum à adubação nitrogenada em sistema de plantio direto. Científica 35: 115-121.

FRAZÃO JJ et al. 2014. Fertilizantes nitrogenados de eficiência aumentada e ureia na cultura do milho. Revista Brasileira de Engenharia Agrícola e Ambiental 18: 12621267.

LEMOS LB et al. 2003. Inoculação de rizóbio e adubação nitrogenada em genótipos de feijoeiro. Revista Agronomia 37: 26-31.

LONDERO PMG et al. 2008. Variabilidade genética para proteína e rendimento de grãos em populações de feijão. Pesquisa Agropecuária Gaúcha 14: 105-111.

LYU X et al. 2015. Polymer-coated tablet urea improved rice yield and nitrogen use efficiency. Agronomy Journal 107: 1837-1844.

MALAVOLTA E. 2006. Manual de nutrição mineral de plantas. São Paulo: Agronômica Ceres. 638p.

MOREIRA GBL et al. 2013. Desempenho agronômico do feijoeiro com doses de nitrogênio em semeadura e cobertura. Revista Brasileira de Engenharia Agrícola e Ambiental 17: 818-823.

NASCIMENTO CAC et al. 2013. Ammonia volatilization from coated urea forms. Revista Brasileira de Ciência do Solo 37: 1057-1063.

OLIVEIRA JA et al. 2014. Volatilização de amônia proveniente de ureia compactada com enxofre e bentonita, em ambiente controlado. Revista Brasileira de Ciência do Solo 38: 1558-1564.

PELEGRIN R et al. 2009. Resposta da cultura do feijoeiro à adubação nitrogenada e à inoculação com rizóbio. Revista Brasileira de Ciência do Solo 33: 219-226.

ROSOLEM CA \& MARUBAYASHI OM. 1994. Seja o doutor do seu feijoeiro. Informações Agronômicas 68: 1-18.

RUFINI M et al. 2011. Simbiose de bactérias fixadoras de nitrogênio com feijoeiro-comum em diferentes valores de pH. Pesquisa Agropecuária Brasileira 46: 81-88. 
SANT'ANA EVP et al. 2010. Adubação nitrogenada na produtividade, leitura Spad e teor de nitrogênio em folhas de feijoeiro. Pesquisa Agropecuária Tropical 40: 491-496.

SANTOS SMC et al. 2016. Fontes e doses de nitrogênio na nutrição, produção e qualidade de grãos do feijoeiro comum. Journal of Agronomic Sciences 5: 69-82.

SILVA FAS \& AZEVEDO CAV. 2006. A New Version of The Assistat-Statistical Assistance Software. In: 4 World congress on computers in agriculture. Anais... Orlando: American Society of Agricultural and Biological Engineers. p.393-396.

SOUZA J et al. 2013. Manejo de nitrogênio revestido com polímeros na cultura do algodão. Acta Iguazu 2: 43-49.

STRECK CA. 2007. Índices e fluxo de água e ar em solos do sul do Brasil. Tese (Doutorado em Ciência do Solo). Santa Maria: UFSM. 95p.

TASCA FA et al. 2011. Volatilização de amônia do solo após a aplicação de ureia convencional ou com inibidor de urease. Revista Brasileira de Ciência do Solo 35: 493-502. TEDESCO MJ et al. 1995. Análise de solo, plantas e outros materiais. 2.ed. Porto Alegre: UFRS. 174p. (Boletim Técnico 5).

VALDERRAMA M et al. 2014. Adubação nitrogenada na cultura do milho com ureia revestida por diferentes fontes de polímeros. Semina: Ciências Agrárias 35: 659-670.

VARGAS MAT et al. 2000. Response of field-grown bean (Phaseolus vulgaris L.) to Rhizobium inoculation and nitrogen fertilization in two Cerrados soils. Biology and Fertility of Soils 32: 228-233.

WATSON CJ et al. 1994. Soil properties and the ability of the urease inhibitor n-(n-butyl) thiophosphoric triamide (nbtpt) to reduce ammonia volatilization from surfaceapplied urea. Soil Biology Biochemistry 26: 1165-1171. 